\title{
Analysis of the Flow Field of Carrier-Based Aircraft Exhaust Jets Impact on the Flight Deck
}

\author{
Yue Kuizhi* \\ Department of Airborne Vehicle Engineering, Naval Aeronautical and Astronautical University, Yantai 264001, China \\ School of Aeronautic Science and Engineering, Beijing University of Aeronautics and Astronautics, Beijing 100191, China
}

\author{
Sun Yicheng* and Liu Hu** \\ School of Aeronautic Science and Engineering, Beijing University of Aeronautics and Astronautics, Beijing 100191, China
}

\section{Guo Weigang*}

Department of Airborne Vehicle Engineering, Naval Aeronautical and Astronautical University, Yantai 264001, China

\begin{abstract}
In order to provide some references for suitability of carrier-based aircrafts, this paper studies the flow field of exhaust jets and its impact on the flight deck. The geometrical models of aircraft carrier and carrier-based aircrafts are firstly built, on which unstructured tetrahedral meshes are generated for numerical analysis. Then, this paper simulates the flow field of exhaust jets to evaluate its impact on the Jet Blast Deflector (JBD) and the flight deck, when four carrier-based aircrafts are ready to start off in the bow. The standard $k-\varepsilon$ equations, three-dimension $N$-S equations and the Computational Fluid Dynamics (CFD) theory are used in the analysis process. To solve the equations, the thermal coupling of the wind and the jet flow are also considered. The velocity and temperature distributions are provided with the simulation of the CFD software, FLUENT. The results indicate that: (1) this analytical method can be used to simulate aerodynamic problems with complex geometrical models, and the results are of high reliability; (2) the safety working area, the installation scheme of the JBD and the arrangement of the take-off position can be optimized through analysis.
\end{abstract}

Key words: Carrier-based Aircraft, Aircraft Carrier, Computational Fluid Dynamics (CFD), Thermal Coupling, Numerical Simulation.

\section{Introduction}

Aircraft carriers are warships that serve as ocean-going airbases. It is extremely dangerous to work on the flight deck of an aircraft carrier. There are not only dozens of aircraft full of ammo, but also equipment linked with thousands of tons of oil, and exhaust jets with high temperatures and high velocity produced by the aero-engines. There are some key problems to be addressed in order to develop suitable aircraft and carriers. Such obstacles include the influence of the exhaust jets deflected by the JBD, the influence of exhaust jets produced by the aircrafts in the temporary standby position, the interaction of wind and exhaust jets, the influence of the exhaust jets on the carried aircraft, maintenance personnel, safeguard vehicles and the working area of equipment. Appropriate measures should be taken in order to address these problems.

The CFD theory is usually used to numerically simulate the high temperature and high velocity flow field on the deck [1]. There have been numerous in-depth studies on the fluid around the ships and aircraft using the CFD theory. The Boeing Company is experienced in commercial airplane
This is an Open Access article distributed under the terms of the Creative Commons Attribution Non-Commercial License (http://creativecommons.org/licenses/bync/3.0/) which permits unrestricted non-commercial use, distribution, and reproduction in any medium, provided the original work is properly cited.

\footnotetext{
(c) * Ph.D.

** Ph.D., Corresponding author: liuhu@buaa.edu.cn
} 
design with the CFD theory, and its use is has become equally as important as the wind tunnel and flight tests [2]. The velocity field and pressure field of the wind over the deck and ship wake have been studied based on the CFD theory [3]. Scale models are used to study different airflow situations for ship air wake [4]. Studies on the flow field of the aircraft carrier have revealed that the size of the hull and the position and shape of the island influences the strength and position of the vortex [5]. Studies have also been carried out on the characteristics and protection measures of corrosion damage of the JBD, and the influence of jet noise on the staff aboard aircraft carriers [6, 7]. An interactive local and global decision support system for aircraft carrier deck scheduling has been designed, which takes the JBD, island, catapult and arrester all into consideration [8]. Furthermore, a study has been carried out on the impact the exhaust jets have on the JBD, however the model is oversimplified with only two cylinder shells and a JBD, without taking the wind over the deck into consideration [9]. Other studies have investigated the application of unstructured meshes based on aeronautical CFD, as well as three-dimensional configurations with leading edge flaps, aileron and wing flaps $[10,11]$. Furthermore, investigations have been carried out into CFD simulation of flow pattern and plume dimensions when submerged into a liquid bath, and vortical flow prediction validation for winged aircraft $[12,13]$. Another study assessed the aircraft flight dynamics of the jet trainer and unmanned combat aerial vehicles [14]. A simulation of the aerodynamics of NAL experimental aircraft with rocket booster has been devised, and a study on the wing-bodyfairing optimization of a civil transport aircraft was carried out that considered the lift, drag and moment of force $[15,16]$. Wing aerodynamics has also been numerically simulated [17]. Despite much having been revealed from the numerous studies of ships and aircrafts with the CFD theory, in-depth studies on the compatibility of aircrafts and the carrier have not been carried out. Also, no studies of influences on the flight have considered thermal coupling with the wind and exhaust jets produced by several carrier-based aircraft.

This paper focuses on the impact of exhaust jets produced by four aircraft using the CFD theory, optimization of the aircraft working areas on the flight deck, and considers the safety areas for maintenance personnel. In doing so, this study hopes to provide a new method to evaluate the suitability of aircraft and aircraft carriers.

\section{Theory basis}

Based on the CFD theory, the impact of the exhaust jets on the deck is numerically simulated. There are five theory bases, including the turbulence model, $N-S$ equations, the energy conservation equation, the temperature unit conversion equation, and a chemical equation.

In the process of CFD numerical simulation, the standard $k$ - $\varepsilon$ equations are applied to simulate the turbulence model, and the three-dimension $N$-S equations are applied in the fluid dynamic theory.

The standard $k-\varepsilon$ equations for turbulence model are as follows [18]:

$$
\begin{aligned}
& \frac{\partial(\rho k)}{\partial t}+\frac{\partial\left(\rho k u_{i}\right)}{\partial x_{i}}=\frac{\partial}{\partial x_{j}}\left[\left(\mu+\frac{\mu_{t}}{\sigma_{k}}\right) \frac{\partial k}{\partial x_{j}}\right]+G_{k}+G_{b}-\rho \varepsilon-Y_{M}+S_{k} \\
& \frac{\partial(\rho \varepsilon)}{\partial t}+\frac{\partial\left(\rho \varepsilon u_{i}\right)}{\partial x_{i}}=\frac{\partial}{\partial x_{j}}\left[\left(\mu+\frac{\mu_{t}}{\sigma_{\varepsilon}}\right) \frac{\partial \varepsilon}{\partial x_{j}}\right]+C_{1 \varepsilon} \frac{\varepsilon}{k}\left(G_{k}+C_{3 \varepsilon} G_{b}\right)-C_{2 \varepsilon} \rho \frac{\varepsilon^{2}}{k}+S_{\varepsilon}
\end{aligned}
$$

where $\rho$ is the air density; $k$ is turbulent kinetic energy; $t$ is time; $u_{i}$ is the mean velocity, $\mu$ is the fluid dynamic viscosity; $\mu_{t}$ is the turbulent dynamic viscosity; $\sigma_{k}$ is the Prandtl Number corresponding to $k$; $G_{k}$ is the item produced by $k$ which is caused by the velocity gradient; $G_{b}$ is the item produced by $k$ which is caused by the buoyancy force; $\varepsilon$ is the turbulent dissipation rate; $Y_{M}$ is the contribution of fluctuation growth rate in turbulence; $S_{k}$ and $S_{\varepsilon}$ are the source items defined by the user; $\sigma_{\varepsilon}$ is the Prandtl Number corresponding to $\varepsilon ; C_{1 \varepsilon}, C_{2 \varepsilon}$ and $C_{3 \varepsilon}$ are the empirical constants.

Three-dimensional $N$-S equations in theoretical fluid dynamics are the momentum conservation equations:

$$
\begin{aligned}
& \frac{\partial \rho u}{\partial t}+\operatorname{div}(\rho u \vec{u})=\operatorname{div}(\mu \operatorname{grad} u)-\frac{\partial p}{\partial x}+S_{u} \\
& \frac{\partial \rho v}{\partial t}+\operatorname{div}(\rho v \vec{u})=\operatorname{div}(\mu \operatorname{grad} v)-\frac{\partial p}{\partial y}+S_{v} \\
& \frac{\partial \rho w}{\partial t}+\operatorname{div}(\rho w \vec{u})=\operatorname{div}(\mu \operatorname{grad} w)-\frac{\partial p}{\partial z}+S_{w}
\end{aligned}
$$

Where $\vec{u}$ is velocity vector; $u, v$ and $w$ are the velocity component of $\vec{u}$ in $\mathrm{x}, \mathrm{y}$ and $\mathrm{z}$ direction, respectively; $p$ is the pressure acting on the fluid element; $\operatorname{div}()$ is divergence; $\operatorname{grad}\left(\right.$ ) is gradient; $S_{u}, S_{v}$ and $S_{w}$ are the generalized source items of momentum conservation equations in $u, v$ and $w$ direction, respectively.

A system with heat transfer is surely to satisfy the energy conservation equation, which is as follows:

$$
\frac{\partial(\rho T)}{\partial t}+\operatorname{div}(\rho \vec{u} T)=\operatorname{div}\left(\frac{k_{r}}{c_{p}} \operatorname{grad} T\right)+S_{T}
$$

Where $T$ is Kelvin temperature, $\mathrm{K} ; k_{r}$ is the heat transfer coefficient; $c_{p}$ is specific heat capacity; $S_{T}$ is viscosity dissipation item. 
The temperature unit conversion equation is as follows:

$T=t+273.15$

Where $t$ is Centigrade temperature, ${ }^{\circ} \mathrm{C}$.

In the combustion model of Fluent, the chemical equation for aviation fuel combusting with air to produce exhaust gases is as follows:

$$
2 \mathrm{C}_{19} \mathrm{H}_{30}+53 \mathrm{O}_{2}=38 \mathrm{CO}_{2}+30 \mathrm{H}_{2} \mathrm{O}
$$

Where $\mathrm{C}_{19} \mathrm{H}_{30}$ is the aviation fuel; $\mathrm{O}_{2}$ is oxygen; $\mathrm{CO}_{2}$ is carbon dioxide; $\mathrm{H}_{2} \mathrm{O}$ is water vapor.

\section{Analysis of multi-flow field of exhaust jets}

During the busiest periods for flight missions on aircraft carriers, there is usually an aircraft ready to take off in front of the JBD, while another is waiting for flight behind the JBD. After one aircraft is catapult launched, the JBD is put down, and then the next aircraft rolls to the take-off position ready to be catapult launched, and at the same time, another aircraft rolls to the standby position. The process goes on like this. There are two take-off positions on the bow of the flight deck and also two on the angled deck.

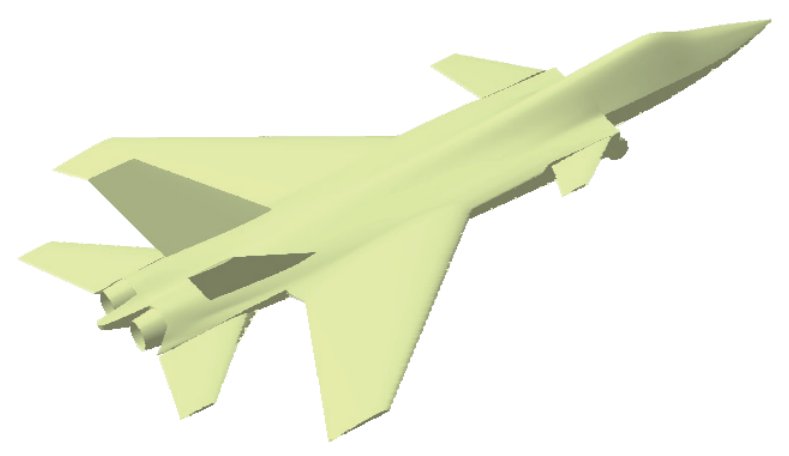

(a) The conceptual designed carrier-based aircraft

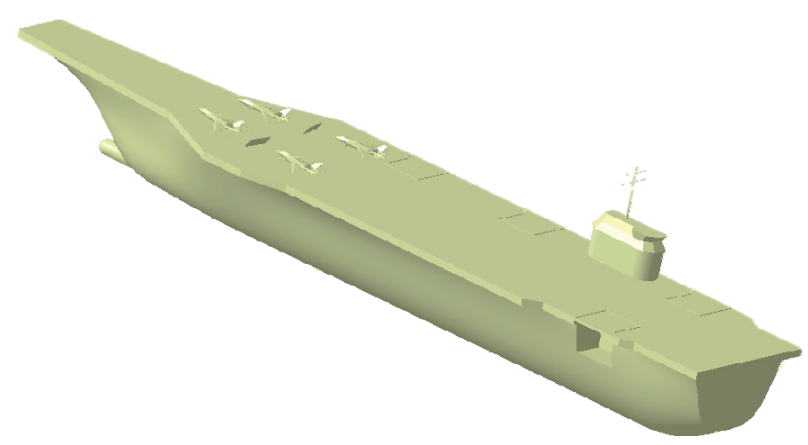

(b) The aircraft carrier and aircrafts system

Fig. 1. Conceptual designed models
This paper numerically simulates the flow field of four aircrafts' exhaust jets, two in the take-off positions and two in the temporary standby positions. The engines are in the fullstress state when in the take-off position and in a crawling state while in the temporary standby position.

Based on the CFD theory, the flow field of four aircrafts' exhaust jets is numerically simulated and the impact on the deck is assessed. The process consists of four parts: geometrical modeling, mesh generation, CFD solving, and CFD analysis.

\subsection{Geometrical model}

The conceptual model of the aircraft carrier is designed with CATIA corresponding to the American Nimitz class nuclear powered aircraft carrier. The carrier-based aircraft is also designed, Fig. 1.

The conceptual designed aircraft carrier is nuclear powered with an angled deck and a straight deck, 4 elevators, 3 arrestors, 4 electromagnetic catapults, 1 island and 1 hangar. The flight deck is $337 \mathrm{~m}$ long and $77 \mathrm{~m}$ wide, with a total height of $76.8 \mathrm{~m}$.

The carrier-based aircraft is a heavy combat fighter designed with a single seat, double engines and three control surfaces. The fighter is equipped with built-in weapon bays, extraversion double vertical tails, a DSI intake port, an S-shape inlet, and fanjets with thrust vectoring nozzles. The carrier-based aircraft is $22.0 \mathrm{~m}$ long, $5.8 \mathrm{~m}$ high, with a wingspan of $16.6 \mathrm{~m}$.

\subsection{Generating meshes}

The FLUENT module in Workbench is used to deal with the geometrical models produced by CATIA. The models are

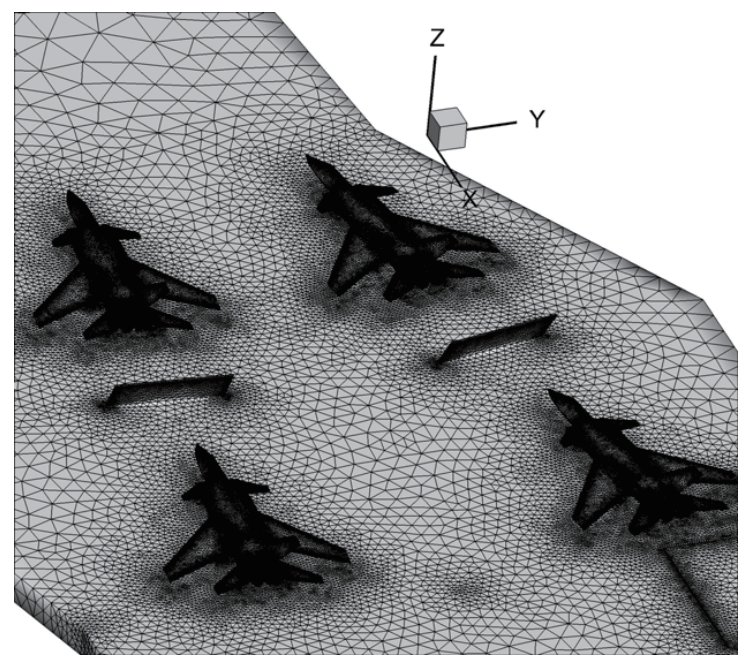

Fig. 2. Meshing 
imported into the Geometry module.

The flow field around the carrier and aircrafts is first generated, after which the sea level is added. The geometrical models and flow field under the sea level are truncated, and what is left is used for the study. Unstructured tetrahedral meshes are then generated on the flow field around the carrier and aircraft, with 35061451 meshes generated altogether. The meshes on the surface of the solid bodies deal with the carrier and aircrafts system, Fig. 2.

After meshing, use the CFD theory to solve the carrier and aircrafts system.

\subsection{CFD solving}

In the solving process, choose the multiphase flow mode in FLUENT is chosen, with air flow and exhaust jets flow set. When the aircraft carrier moves as fast as 24 knots per hour, the velocity of far field air flow is $12.34 \mathrm{~m} / \mathrm{s}$, causing a wind to blow over the deck, while the engines produces a high temperature and high velocity flow field. The model is set with the energy conservation equation, standard $k-\varepsilon$ equations and three-dimensional $N-S$ equations. The boundary conditions are set as follows: (1) the velocity of far field as $12.34 \mathrm{~m} / \mathrm{s}$; (2) the temperature of incoming flow as $26.85^{\circ} \mathrm{C}$; (3) the temperature of the sea water homoeothermic as $26.85^{\circ} \mathrm{C}$; (4) the components of air as $78 \%$ nitrogen, $21 \%$ oxygen, and $1 \%$ other gases.

The initial conditions of the engines are set as follows: (1) in the full-stress state, the exhaust gas temperature after turbine as $750^{\circ} \mathrm{C}$, the inflow velocity as $60 \mathrm{~m} / \mathrm{s}$, and the exit flow velocity as $200 \mathrm{~m} / \mathrm{s}$; (2) in the crawling state, the exhaust gas temperature after turbine as $500^{\circ} \mathrm{C}$, the inflow velocity as $30 \mathrm{~m} / \mathrm{s}$, and the exit flow velocity as $100 \mathrm{~m} / \mathrm{s}$.

By using the time marching method to solve the flow field in FLUENT, the second upwind scheme is used in the coupled solution of the N-S equations, energy equation and turbulence equation.

\subsection{CFD analysis}

When numerically simulating the carrier and aircraft systems, the initial conditions are set as follows: (1) in the $\mathrm{XY}$ plane, the angle between the right JBD and the X-axis of the carrier as $80^{\circ}$; (2) in the XY plane, the angle between the left JBD and the $\mathrm{X}$-axis of the carrier as $83^{\circ}$; (3) the $\mathrm{X}$ axis of the aircraft perpendicular to the $\mathrm{Y}$ axis of the JBD.

For consideration of the thermal coupling of the wind and the exhaust jets, the aircraft in the take-off positions are in the full-stress state, and the aircrafts in the temporary standby positions are in the crawling state. FLUENT is used to simulate the flow field of multi-exhaust jets in order to evaluate the impact to the flight deck. After the CFD simulation, the flow field of multiple aircraft and the temperature distributions along the carrier axis are shown, Fig. 3 and Fig. 4.

The CFD simulation of multi-exhaust jets consists of isosurface of velocity, isosurface of temperature and a nephogram of temperature distribution, Fig. 3(a), 3(b) and 3(c).

Conclusions that can be drawn from Fig. 3 are that: (1) the exhaust jets are reflected upward by the JBD to avoid burning the aircraft in the standby position; (2) though in the crawling state, the exhaust jets produced by aircraft in the standby positions still influence a large part of the flight deck; (3) the left JBD has a better diversion effect than the right one, since more exhaust gases are diverted outwards from the deck by the left JBD, while more exhausted gases are directed inwards by the right one. The reason lies in that, in the XY plane, the angle between the left JBD and the X-axis of the carrier is $83^{\circ}$, bigger than that of the right one, making it easier for the exhaust gas to combine with the wind. If the angle between the JBD and the X-axis of the carrier was $90^{\circ}$, the diversion effect would be much better. (4) The exhaust jets produced by the aircraft in the left standby position influence a larger area than the right one due to the angle between the $\mathrm{X}$-axis of the aircraft and the $\mathrm{X}$-axis of the carrier being just $7^{\circ}$, smaller than that of the right one. So the nozzle of the right aircraft deflects more outwards, making the exhaust jets impact less on the flight deck.

When four aircraft are ready to start off, the temperature distributions along the carrier axis are shown, Fig. 4.

Figure 4(a) indicates that: (1) at 102 104m on the X-axis, the temperature reaches up to $1023.15 \mathrm{~K}$, exactly the position of the full-stress state nozzle; (2) at 141 143m on the X-axis, the temperature reaches up to $773.15 \mathrm{~K}$, where the nozzle of the aircraft lies; (3) at 106 141m on the X-axis, with the temperature ranging from $725 \mathrm{~K}$ to $373 \mathrm{~K}$, a large area is influenced by the exhaust jets; (4) at 110 163m on the $\mathrm{X}$-axis, the temperature of the exhaust gases produced by the full-stress state engines drops from $713 \mathrm{~K}$ to $350 \mathrm{~K}$; (5) at $160 \sim 310 \mathrm{~m}$ on the $\mathrm{X}$-axis, the temperature of the exhaust gas produced by the crawling state engines drops from $470 \mathrm{~K}$ to $350 \mathrm{~K}$. Therefore, when several aircrafts are working on the bow, the exhaust gases influences a large area of the flight deck. At this point, anyone in this area would be at a high risk of death or injury by burning, and so workers should be forbidden from entering it.

Figure 4(b) indicates that: (1) at 13 16m and $-10 \sim-13 \mathrm{~m}$ on the Y-axis, the temperature reaches up to $1023.15 \mathrm{~K}$, exactly the position of the full-stress state nozzle; (2) at 21 24m 
and $-15 \sim-18 \mathrm{~m}$ on the Y-axis, the temperature reaches up to $773.15 \mathrm{~K}$ where the nozzle of the crawling state aircraft is; (3) in the large area from $-40 \sim 40 \mathrm{~m}$ of the Y-axis, the temperature of exhaust gases is above $350 \mathrm{~K}$.

Figure 4(c) indicates that: (1) at $2 \sim 3 \mathrm{~m}$ of Z-axis, the temperature reaches up to $1023.15 \mathrm{~K}$, exactly the position of the full-stress state nozzle (The flight deck plane is on the position where $\mathrm{Z}$ is $0.5 \mathrm{~m}$ ); (2) at $0 \sim 6.5 \mathrm{~m}$ on the $\mathrm{Z}$-axis, the temperature influenced by the exhaust gases ranges from $1023.15 \mathrm{~K}$ to $350 \mathrm{~K}$; (3) above $6.5 \mathrm{~m}$ on the $\mathrm{Z}$-axis, the temperature is below $350 \mathrm{~K}$.

Compared with the results of the scale experiments in the proving ground, the results of the simulation are almost consistent in terms of temperature and velocity. The data acquisition process of the experiments is as follows: (1) in an area of $200 \mathrm{~m} \times 80 \mathrm{~m}$ behind the aircraft, there are altogether

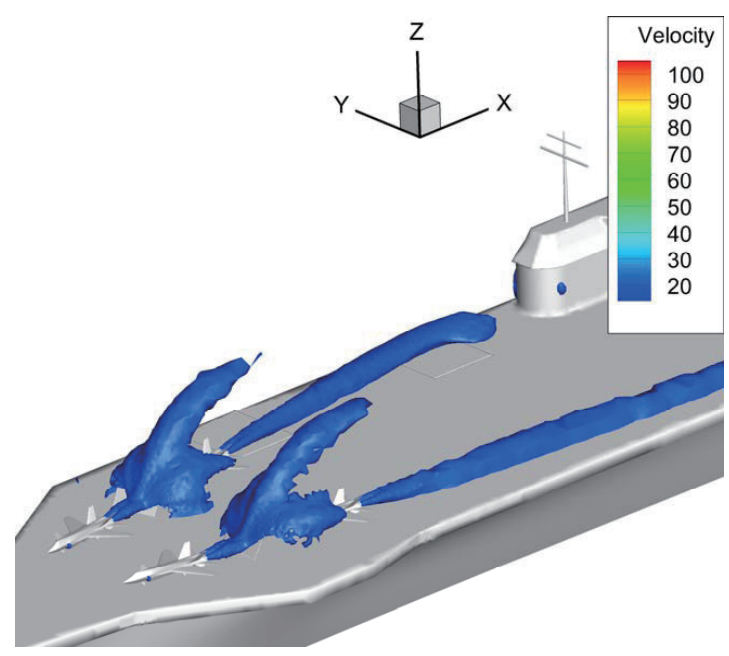

(a) Isosurface of velocity $(v>20 \mathrm{~m} / \mathrm{s})$
180 sampling points arranged on the deck in three levels, $1 \mathrm{~m}, 2 \mathrm{~m}$ and $3 \mathrm{~m}$, with each level containing 60 points; (2) each sampling point collects data of temperature and velocity while the engines of the aircraft are working; (3) by comparing the experimental data with the simulation of the CFD, conclusions can be drawn. The accuracy of the simulation is up to $95.2 \%$, proving the feasibility of the CFD technique and the application of the numerical simulation.

\section{Conclusion}

Based on the CFD theory, for analysis of the thermal coupling of the wind and the exhaust jets, the flow field when four aircraft are ready to start off on the bow of the flight deck has been numerically simulated. After the simulation,

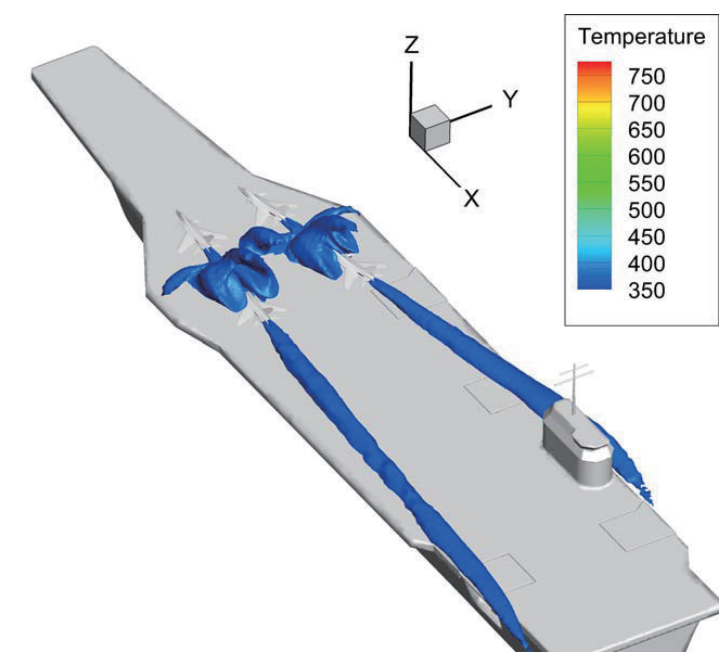

(b) Isosurface of temperature ( $T>373 \mathrm{~K})$

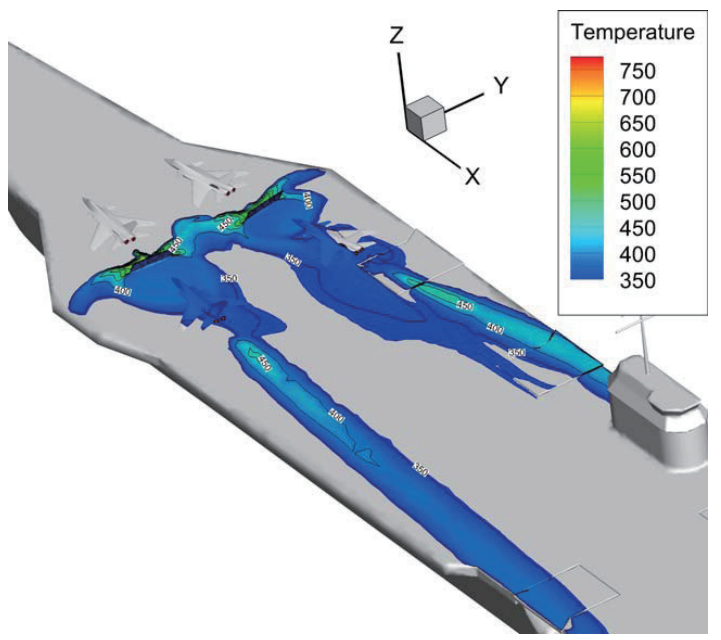

(c) Nephogram of temperature distribution

Fig. 3. The CFD simulation of multi-exhaust jets 


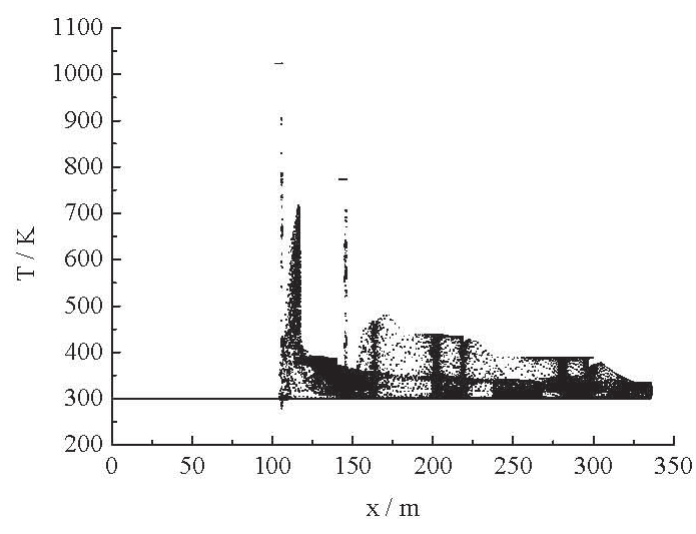

(a) The temperature distribution along $\mathrm{X}$-axis

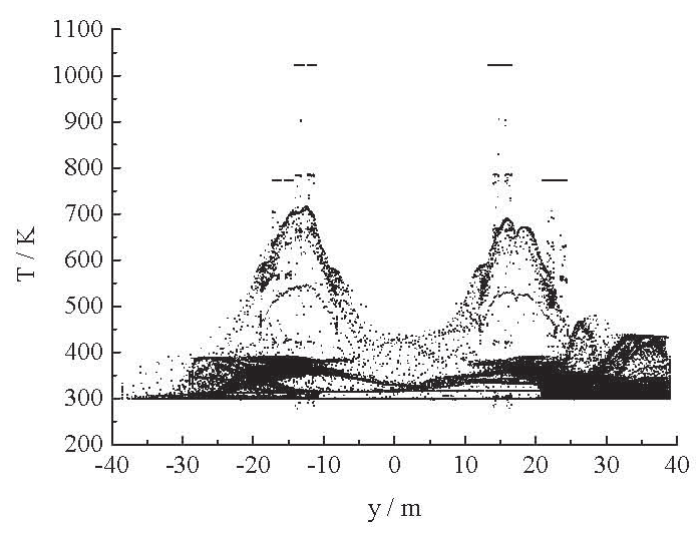

(b) The temperature distribution along Y-axis

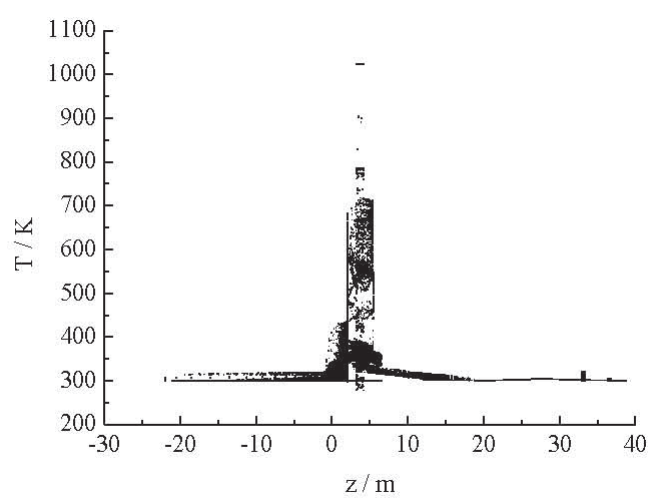

(c) The temperature distribution along Z-axis

Fig. 4. The temperature distribution along the carrier axis

conclusions can be drawn as follows:

(1) The numerical simulation can solve fluid dynamic problems with complex shape based on the CFD theory, with CATIA developing the geometrical models and Workbench solving the simulation. This provides a useful method for solving similar CFD problems with complex shape.

(2) It is advised that staff do not enter the following areas due to risk of injury by burning or death: within $53 \mathrm{~m}$ behind the JBD, $22.5 \mathrm{~m}$ along the centerline of the JBD, and at 1.5 4.5m above the flight deck, .

(3) The JBD should withstand high temperatures. After consideration of the thermal coupling of the wind and the exhaust gases, the temperature of the central JBD is above $700 \mathrm{~K}$. As such, cooling measures should be seriously considered.

(4) In the XY plane, the angle between the JBD and the $\mathrm{X}$-axis of the carrier should approach $90^{\circ}$, helping the exhaust gases flow outwards when coupled with the wind.

(5) The impact of the exhaust gases decreases after being reflected by the JBD; while the exhaust gases produced by aircraft in the standby position impact the deck severely. Suggestions are also made that the nozzle of the standby position aircraft deflects outwards from the deck to reduce the influence on staff, vehicles and other aircraft parked in the area.

\section{References}

[1] Levy, D.W., Zickuhr, T., Vassberg, J., "Summary of data from the first AIAA CFD drag prediction workshop," AIAA 2002-0841,2012.

[2] Forrester, T.J., Edward, N.T., Jong, Y., “Thirty years of development and application of CFD at Boeing Commercial Airplanes, Seattle ," Computers and Fluids, Vol.34,No.10, 2005, pp.1115-1151.

[3] Sun, T., Xiao, T.H., Zhang, Y.C., "Studies on CFD Based Deck Flow Field Modeling of Carrier-borne Aircraft Flight Simulator," Journal of System Simulation, Vol.25, No.5, 2013, pp.82-85. 
[4] Lu, C., Jiang, Z.F., Wang, T., "In fluencies of different airflow situations for ship air wake," Ship Science and Technology, Vol.31, No.9, 2009, pp.38-42.

[5] Gao, Y., Liu, C.M., He, Z., "Research on CVN deck vorticss structure characteristics caused by wind direction changes," Ship Science and Technology, Vol.31, No.3, 2013, pp.310-315.

[6] Yang, M.S., Wen, D.H., Wang, H.D., "Study on the Characteristics and Protection Measures of Corrosion Damage of the Jet Blast Deflector," Equioment Environmental Engineering, Vol.10, No.6, 2013, pp.93-97.

[7] Aubert, A., McKinley, R., "Measurements of Jet Noise Aboard US Navy Aircraft Carriers," AIAA Centennial of Naval Aviation Forum "100 Years of Achievement and Progress", 2122 September 2011, Virginia Beach, VA, AIAA 2011-6947.

[8] Jason, C.R., Cummingsb, M. L., Nick, R., "Designing an Interactive Local and Global Decision Support System for Aircraft Carrier Deck Scheduling," Infotech@Aerospace 2011,29-31 March 2011, St. Louis, Missouri, AIAA 2011-1516.

[9] He, Q.L., Lu, J., Yang, D.P., "Numerical Simulation of the Flow field of Carrier-Based Aircraft Exhaust Jet," Chinese Journal of ship Research, Vol. 8, No.5, 2013, pp.13-18+51.

[10] Kazuhiro, N., "Aeronautical CFD in the age of Petaflops-scale computing: From unstructured to Cartesian meshes," European Journal of Mechanics / B Fluids, Vol.40,No.1, 2013, pp.75-86.

[11] Normann, K., Andreas, K., "Automatic Transition
Prediction for three-dimensional configurations with focus on industrial application," Journal of Aircraft, Vol.48, No.6, 2011, pp.1878-1887.

[12] Sagar, S.G., Sachin, K.D., Jyeshtharaj, B.J., "CFD simulation of flow pattern and plume dimensions in submerged condensation and reactive gas jets into a liquid bath," Chemical Engineering Science, Vol.63,No.9, 2008, pp.2420-2435.

[13] Vallespin, D., Ronch, A.D., Badcock, K.J., "Vortical flow Prediction Validation for an unmanned combat air vehicle model," Journal of Aircraft, Vol.48, No.6, 2011, pp.1948-1959.

[14] Vallespin, D., Badcock, K.J., Ronch, A.D., "Computational fluid dynamics framework for aerodynamic model assessment," Progress in Aerospace Sciences, Vol.52, No.1, 2012, pp.2-18.

[15] Fumiya, T., Takeshi, F., "CFD computa- tions of NAL experimental airplane with rocket booster using overset unstructured grids," Int. J. Numer. Meth. Fluids, Vol.48, No. 8, 2005, pp.801-818.

[16] Song, W.B., Lv, P.P., “Two-Level Wing-Body-Fairing Optimization of a Civil Transport Aircraft," Journal of Aircraft, Vol.48, No.6, 2011, pp. 2114-2121.

[17] Rumsey, C.L., Slotnick, J.P., Long, M., "Summary of the First AIAA CFD High-Lift Prediction workshop," Journal of Aircraft, Vol.48, No.6, 2011, pp.2068-2079.

[18]Yu, X.H., Ma, J.Z., Hu, Z.G., "An investion of the airfarame inlet integration flow characteristics," Acta Aerodynamica Sinica, Vol.26, No.2, 2008, pp.150-155. 